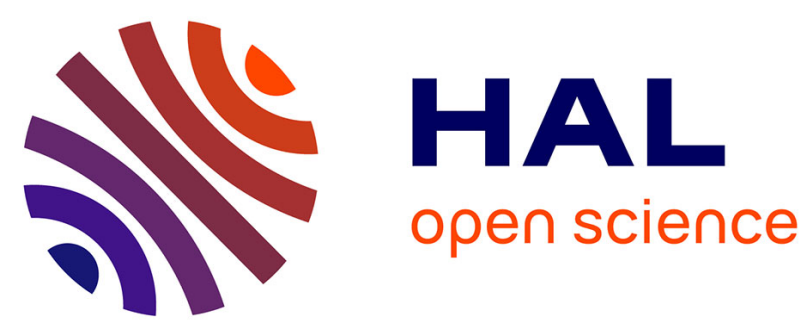

\title{
Realistic measurement uncertainties for marine macronutrient measurements conducted using gas segmented flow and Lab-on-Chip techniques
}

A.J. Birchill, G. Clinton-Bailey, R. Hanz, E. Mawji, T. Cariou, C. White, S.J. Ussher, P.J. J Worsfold, E. P Achterberg, M. Mowlem

\section{To cite this version:}

A.J. Birchill, G. Clinton-Bailey, R. Hanz, E. Mawji, T. Cariou, et al.. Realistic measurement uncertainties for marine macronutrient measurements conducted using gas segmented flow and Lab-on-Chip techniques. Talanta, 2019, 200, pp.228-235. 10.1016/j.talanta.2019.03.032 . hal-02182171

\section{HAL Id: hal-02182171 \\ https://hal.sorbonne-universite.fr/hal-02182171}

Submitted on 12 Jul 2019

HAL is a multi-disciplinary open access archive for the deposit and dissemination of scientific research documents, whether they are published or not. The documents may come from teaching and research institutions in France or abroad, or from public or private research centers.
L'archive ouverte pluridisciplinaire HAL, est destinée au dépôt et à la diffusion de documents scientifiques de niveau recherche, publiés ou non, émanant des établissements d'enseignement et de recherche français ou étrangers, des laboratoires publics ou privés. 


\title{
Realistic measurement uncertainties for marine macronutrient measurements conducted using gas segmented flow and Lab-on-Chip techniques
}

\author{
Birchill A.J. $^{\mathrm{a}, *}$, G. Clinton-Bailey ${ }^{\mathrm{a}}$, R. Hanz ${ }^{\mathrm{a}}$, E. Mawji ${ }^{\mathrm{b}}$, T. Cariou ${ }^{\mathrm{c}}$, C. White ${ }^{\mathrm{d}}$, S.J. Ussher ${ }^{\mathrm{d}}$, \\ P.J. Worsfold ${ }^{\mathrm{d}}$, E.P. Achterberg ${ }^{\mathrm{e}}$, M. Mowlem ${ }^{\mathrm{a}}$ \\ ${ }^{a}$ Ocean Technology and Engineering, National Oceanography Centre, European Way, Southampton SO14 3ZH, United Kingdom \\ ${ }^{\mathrm{b}}$ Ocean Biogeochemistry and Ecosystems, National Oceanography Centre, European Way, Southampton SO14 3ZH, United Kingdom \\ ${ }^{\mathrm{c}}$ Sorbonne Universités, UPMC Univ Paris 06, CNRS, Fédération de Recherche (FR2424), Station Biologique de Roscoff, 29680 Roscoff, France \\ ${ }^{\mathrm{d}}$ School of Geography, Earth and Environmental Sciences, University of Plymouth, Drake Circus, Plymouth PL4 8AA, United Kingdom \\ e GEOMAR Helmholtz Centre for Ocean Research, 24148 Kiel, Germany
}

Keywords:

Macronutrient

Nitrate

Phosphate

Intercomparison

Measurement uncertainty

Lab-on-Chip

Segmented flow

\begin{abstract}
A B S T R A C T
Accurate and precise measurements of marine macronutrient concentrations are fundamental to our understanding of biogeochemical cycles in the ocean. Quantifying the measurement uncertainty associated with macronutrient measurements remains a challenge. Large systematic biases (up to 10\%) have been identified between datasets, restricting the ability of marine biogeochemists to distinguish between the effects of environmental processes and analytical uncertainty. In this study we combine the routine analyses of certified reference materials (CRMs) with the application of a simple statistical technique to quantify the combined (random + systematic) measurement uncertainty associated with marine macronutrient measurements using gas segmented flow techniques. We demonstrate that it is realistic to achieve combined uncertainties of $\sim 1-4 \%$ for nitrate + nitrite $(\Sigma \mathrm{NOx})$, phosphate $\left(\mathrm{PO}_{4}{ }^{3-}\right)$ and silicic acid $\left(\mathrm{Si}(\mathrm{OH})_{4}\right)$ measurements. This approach requires only the routine analyses of CRMs (i.e. it does not require inter-comparison exercises). As CRMs for marine macronutrients are now commercially available, it is advocated that this simple approach can improve the comparability of marine macronutrient datasets and therefore should be adopted as 'best practice'.

Novel autonomous Lab-on-Chip (LoC) technology is currently maturing to a point where it will soon become part of the marine chemist's standard analytical toolkit used to determine marine macronutrient concentrations. Therefore, it is critical that a complete understanding of the measurement uncertainty of data produced by LoC analysers is achieved. In this study we analysed CRMs using 7 different LoC $\Sigma \mathrm{NOx}$ analysers to estimate a combined measurement uncertainty of $<5 \%$. This demonstrates that with high quality manufacturing and laboratory practices, LoC analysers routinely produce high quality measurements of marine macronutrient concentrations.
\end{abstract}

\section{Introduction}

Marine primary production sustains commercial fisheries [1] and influences atmospheric carbon dioxide concentrations [2]. The biomass of marine primary producers is comprised of a suite of nutrients, which must be acquired from surrounding seawaters. The regulatory role that the availability of nutrients in seawater has upon marine primary production is well established [3]. In particular, the low availability of nitrogen and phosphorus is known to limit primary production in much of the open ocean $[4,5]$. In contrast, anthropogenic perturbation of nitrogen and phosphorus cycles has resulted in eutrophic conditions in some coastal waters, leading to an increase in the occurrence of harmful algal blooms [6] and regions of oxygen deficiency termed 'dead zones' [7].

In order to understand and quantify the processes leading to oligotrophy and eutrophy, marine chemists routinely determine the concentration of nitrite + nitrate (hereafter $\Sigma \mathrm{NOx}$ ), soluble reactive phosphorus (hereafter $\mathrm{PO}_{4}{ }^{3-}$ ) and silicic acid (hereafter $\mathrm{Si}(\mathrm{OH})_{4}$ ) in seawater. Collectively these inorganic species are referred to as macronutrients and are considered an 'essential ocean variable' by The

\footnotetext{
* Corresponding author.

E-mail address: anchill@noc.ac.uk (A.J. Birchill).
} 
Global Ocean Observing System (http://www.goosocean.org/). The most common method of detection used to determine macronutrient concentrations in seawater is spectrophotometry. Spectrophotometry relies on the formation of a coloured dye, whereby the intensity of the dye is proportional to concentration of the analyte of interest. The 'Beer-Lambert-Bouguer' law is then used to relate the absorbance of light by the dye to the concentration of the analyte in solution. The Griess test is the most widely used technique for the determination of $\mathrm{NO}_{3}^{-}$[8-10]. The Griess reagent contains two chemicals, sulphanilamide and $\mathrm{N}-\left(1\right.$ napthyl)ethlyenediamine; under acidic conditions $\mathrm{NO}_{2}^{-}$ converts sulphanilamide to a diazonium ion that readily couples with $\mathrm{N}$-(1 napthyl)ethlyenediamine to form a coloured azo dye. The intense red/pink colour is measurable at $\sim 520-550 \mathrm{~nm}$. To detect $\Sigma \mathrm{NOx}$, any nitrate must first be reduced to nitrite. This is typically achieved by passing the sample through a copper-coated cadmium reduction column. 'Molybdenum blue' is the most widely used technique for the determination of $\mathrm{PO}_{4}{ }^{3-}$ and $\mathrm{Si}(\mathrm{OH})_{4}[9,11-15]$. Orthophosphate and molybdate react in an acidic medium to form 12-molybdophophoric acid, which is then reduced to phosphomolybdate blue by ascorbic acid. The intense blue colour formed is measurable at $\sim 700$ or $\sim 880 \mathrm{~nm}$. A similar approach is typically adopted to measure $\mathrm{Si}(\mathrm{OH})_{4}$, whereby $\mathrm{Si}$ $(\mathrm{OH})_{4}$ and molybdate react in an acidic medium to form the silicomolybdic acid, which is then reduced to silicomolybdate blue. The intense blue colour is measurable at $\sim 810 \mathrm{~nm}$, with a smaller peak observed at $\sim 600-660 \mathrm{~nm}$.

Traditionally, macronutrient concentrations are determined following manual sampling of seawater; water is collected at known times and depths and then preserved for laboratory analysis on board ship or on land. Spectrophotometric detection has been combined with gas segmented continuous flow techniques to become the most common method of macronutrient analysis in seawater $[12,16]$. This allows for the analysis of large numbers (100 s) of samples per day, which is typically required during research cruises. The requirement for high sample throughput means that even short term analytical uncertainties are often not reported for individual macronutrient measurements (i.e. the sample is analysed once rather than in triplicate). Increased automation has led to a decrease in measurement quality [17] and analyses of marine macronutrient concentrations reported at cross-over stations (i.e. a location at which two research cruise tracks cross and seawater was sampled at the same geographic location) indicated that systematic biases of up to $10 \%$ can exist between datasets $[18,19]$. Systematic bias is the difference between the estimated value and the 'true' value, and neglecting systematic bias can lead to an underestimation of analytical uncertainty [20-24].

An approach to account for systematic bias in marine macronutrient datasets is to use the observed offset in concentrations reported at crossover stations or reference climatology datasets to 'adjust' macronutrient concentrations [17-19]. In surface waters, seasonal processes have large impacts on macronutrient concentrations [e.g. 25], restricting this approach to deep waters where inorganic nutrient concentrations are more stable and typically elevated due to the remineralisation of sinking organic matter. In addition, this approach requires pre-existing data in the first instance, which can be problematical in under-sampled remote ocean regions $[17,18]$, and if there is a pre-existing bias in the historic dataset then the mean, and subsequent adjustments, are off-set from the true value. Moreover, there always exists a danger of over correcting and removing features that result from environmental processes. For instance, comparisons are typically made between water masses; comparisons are made between seawater samples with a similar density rather than simply those collected at a similar depth. Hydrographic fluctuations can introduce natural variability in deep water nutrient concentrations. The Atlantic Ocean for instance is influenced by Antarctic Bottom Water containing high $\mathrm{Si}(\mathrm{OH})_{4}$ concentrations and by Mediterranean Outflow Water that has different nutrient concentrations to other Atlantic water masses with a similar density. Therefore applying an adjustment to regions where the prevalence of these waters masses varies requires a larger tolerance for natural variation [18].

Producing realistic uncertainty estimates for marine macronutrient data remains a challenge for marine chemists. The 4th Intergovernmental Panel on Climate Change report stated that "Uncertainties in deep ocean nutrient observations may be responsible for the lack of coherence in the nutrient changes. Sources of inaccuracy include the limited number of observations and the lack of compatibility between measurements from different laboratories at different times" [26]. A current aim of The Scientific Committee on Oceanic Research (SCOR) working group 147 (https://scor-int.org/group/147/) and Optimising and Enhancing the Integrated Atlantic Ocean Observing Systems (AtlantOS; https://www.atlantos-h2020.eu/) is to improve the comparability of global nutrient data. Efforts to achieve this aim include the continuation of ongoing laboratory inter-comparison exercises [27-31] and updating the best practice manuals for making marine nutrient measurements [16]. A unifying recommendation of the inter-comparison exercises was that seawater macronutrient certified reference materials (CRMs) be developed and routinely analysed in order to improve nutrient data comparability. Stable CRMs for marine nutrients are now commercially available [e.g. 32, 33], providing a powerful tool to assess systematic bias [34].

The oceanographic community is currently experiencing the development of novel Lab-on-Chip (LoC) microfluidic analysers with the capability to measure $\Sigma \mathrm{NOx}$ and $\mathrm{PO}_{4}{ }^{3-}$ at nanomolar concentrations [e.g. 35-37]. Microfluidic technology allows miniaturisation of existing chemical analytical methods, thus LoC analysers can be deployed on moorings and mobile platforms [38,39]. Consequently, LoC analysers have the potential to greatly enhance our ability to sample the environment, and by measuring in-situ, remove the need to preserve collected samples $[40,41]$. LoC nutrient analysers have been deployed with the aim of elucidating the environmental processes governing nutrient distributions [38,39,42], moving them from developmental stages to routine scientific use. Consequently, it is critical that a concerted effort is made to ensure that we understand the analytical uncertainty associated with data produced by LoC analysers.

The aim of this communication is to present the application of a simple statistical approach for quantifying the combined (random uncertainty + systematic bias) measurement uncertainty of marine nutrient measurements made using gas segmented flow techniques and novel LoC platforms. This approach utilises commercially available CRMs and requires no costly inter laboratory comparisons or cross-over stations. Moreover, it accounts for short term and intermediate sources of random measurement uncertainty (e.g. changing laboratory conditions, difference reagent batches, different analysts) and systematic bias.

\section{Materials and methods}

A detailed description of analytical methods can be found in the Supporting information. Standard gas segmented flow techniques with spectrophotometric detection were used for the determination of $\Sigma \mathrm{NOx}$, $\mathrm{PO}_{4}{ }^{3-}$ and $\mathrm{Si}(\mathrm{OH})_{4}[11,12]$. The spectrophotometric methods used in all techniques were the Griess (for $\mathrm{NNOx}$ ) and molybdenum blue (for $\mathrm{PO}_{4}{ }^{3-}$ $\left.\& \mathrm{Si}(\mathrm{OH})_{4}\right)$ assays. $\Sigma \mathrm{NOx}$ measurements for both standard gas segmented flow techniques require that $\mathrm{NO}_{3}{ }^{-}$is reduced to $\mathrm{NO}_{2}{ }^{-}$by passing the solution through a copper coated cadmium column.

The LoC analysers used in this study have been described in detail elsewhere [35-37,43]. Briefly, LoC analysers are composed of a three layer poly(methyl methacrylate) chip with precision milled micro channels (150 $\mu \mathrm{m}$ wide, $300 \mu \mathrm{m}$ deep), mixers and optical components consisting of Light Emitting Diodes and photodiodes. Electronics, valves and syringe pumps are mounted on the chip, which is encased in a dark water tight PVC tube. In addition, the $\Sigma \mathrm{NOx}$ analyser has an off-chip copper coated cadmium-column for the reduction of $\mathrm{NO}_{3}{ }^{-}$to $\mathrm{NO}_{2}^{-}$. A manifold diagram of the $\Sigma \mathrm{NOx}$ analyser can be found in the Supporting 
Information. The analytical procedure used to determine $\Sigma \mathrm{NOx}$ is as follows; $69 \mu \mathrm{l}$ of blank, sample or standard solution and $69 \mu \mathrm{l}$ of imidazole buffer is injected into the chip via a serpentine mixer upstream of an off-chip copper coated cadmium column, this solution is flushed through the chip to waste. This process was repeated 4 times to fully flush the chip and prevent signal dilution or enhancement due to carryover from previous solutions. On the fifth flush, $69 \mu \mathrm{l}$ of Griess reagent was mixed via an additional serpentine mixer downstream of the copper coated cadmium column. The solution was then left in the measurement cells for $110 \mathrm{~s}$ to allow for colour development. Throughout the analytical cycle the voltage output of the photodiodes was recorded at $1 \mathrm{~s}$ intervals. For each calibrated measurement, an analytical cycle consisted of the analysis of a blank solution, sample (CRM) and then a standard solution. Thus a fully calibrated measurement took $19 \mathrm{~min}$ and each sample has an associated blank and standard from which to calculate the absorbance. The limit of detection of the $\Sigma$ NOx analyser, defined as 10 times the standard deviation of a $0.05 \mu \mathrm{M}$ nitrate standard, has been reported as $0.025 \mu \mathrm{M}$ [35], two orders of magnitude below the concentration of CRMs analysed in this study.

\subsection{Certified reference materials}

In order to quantify the accuracy of our analyses and to calculate our uncertainty, CRMs were routinely analysed. All CRMs used in this study were sourced from KANSO Co., Ltd. (http://www.kanso.co.jp/ eng/index.html). The CRMs were filtered $(0.45 \mu \mathrm{m})$ natural seawater samples collected from the Pacific Ocean, which were autoclaved and stored in $100 \mathrm{~mL}$ polypropylene bottles, which were vacuum sealed in an aluminium-film bag. The concentrations were certified using the Griess and Molybdenum blue colorimetric assays, the same techniques as used in this study. Certified reference material CD comprised of $81 \%$ surface seawater from the Pacific Ocean $\left(29.58^{\circ} \mathrm{N}, 149.15^{\circ} \mathrm{E}\right)$ and $19 \%$ of seawater collected at $397 \mathrm{~m}$ depth in Suruga Bay, Japan. Certified reference material CJ comprised of $44 \%$ surface seawater from the Pacific Ocean $\left(32^{\circ} \mathrm{N}, 144^{\circ} \mathrm{E}\right)$ and $56 \%$ of seawater collected at $397 \mathrm{~m}$ depth in Suruga Bay, Japan. Certified reference material CB comprised of $44 \%$ seawater collected from the Pacific Ocean at $1187 \mathrm{~m}\left(48.9^{\circ} \mathrm{N}\right.$, $166.6^{\circ} \mathrm{E}$ ) and $56 \%$ of seawater collected at $397 \mathrm{~m}$ depth in Suruga Bay, Japan. Certified reference material BW was collected at $270 \mathrm{~m}$ depth in Suruga Bay, Japan. Certified reference material BZ was collected from the Pacific Ocean at $1187 \mathrm{~m}$ depth $\left(48.9^{\circ} \mathrm{N}, 166.6^{\circ} \mathrm{E}\right)$.

\subsection{Statistical methods}

Data were generated from the analyses of CRMs by two gas segmented flow analysers and seven LoC analysers. A schematic of the experimental design is displayed in Fig. 1. Analytical uncertainties were calculated via the NordTest ${ }^{\mathrm{TM}}$ approach [44], which has recently been applied to marine trace metal studies $[20,23,45]$. The Nordtest ${ }^{\mathrm{TM}}$ approach combines random effects, including intermediate sources of analytical uncertainty (e.g. different reagents and standards, different analysts, changing laboratory conditions, different LoC analysers), and the uncertainty resulting from systematic bias. Systematic bias was estimated via the analyses of CRMs. Consequently, the Nordtest ${ }^{\mathrm{TM}}$ approach accounts for both random and systematic effects and will therefore produce a higher analytical uncertainty than the typically reported standard deviation of replicate sample measurements, which only accounts for sources of short-term random uncertainty. As this higher analytical uncertainty incorporates more of the possible sources of uncertainty, it is considered a more realistic and reliable estimate. An example Microsoft Excel ${ }^{\mathrm{TM}}$ template can be found in the Supporting information. All uncertainties calculated in this study are presented as relative uncertainties.

The combined uncertainty $\left(\mathrm{u}_{\mathrm{c}}\right)$ was estimated from the sum of the squares of two independent uncertainty estimates:
$\mathrm{u}_{\mathrm{c}}=\sqrt{\left(\mathrm{u}(\mathrm{Rw})^{2}+\mathrm{u}(\text { bias })^{2}\right)}$

where $\mathrm{u}(\mathrm{Rw})$ represent within laboratory reproducibility and $\mathrm{u}(\mathrm{bias})$ represents method and laboratory systematic bias. The laboratory reproducibility includes the pooled standard deviation of the measurements of the same samples (or CRMs) over a period of several months. As nutrient samples are not stable for this length of time once opened, fresh (within 1 week of opening) CRM samples were analysed and treated as the same sample. Method and laboratory systematic bias was estimated after Eq. (2).

$\mathrm{u}($ bias $)=\sqrt{ }\left(\mathrm{RMS}_{\text {bias }}{ }^{2}+\mathrm{u}(\text { Cref })^{2}\right)$

where $\mathrm{RMS}_{\text {bias }}{ }^{2}$ is the root mean square of the bias value (Eq. (3)) and $\mathrm{u}$ (Cref) is the uncertainty of the certified reference value (Eq. (4)).

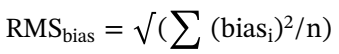

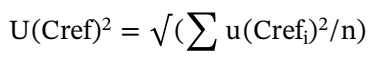

where bias $_{\mathrm{i}}$ is the percentage difference between the mean concentration value determined and the certified value of a CRM, $u\left(\mathrm{Cref}_{\mathrm{i}}\right)$ being the uncertainty of the certified reference value and $n$ being the number of CRMs used. Each estimate used the analyses of at least two different CRMs, each with different macronutrient concentrations. Final uncertainties were determined as $\mathrm{u}_{\mathrm{c}}(\mathrm{k}=1)$.

\section{Results and discussion}

\subsection{Gas segmented flow analysis}

CRM analyses were conducted using gas segmented flow analysis during a research cruise in the South Atlantic Ocean in 2018 on board the RRS. James Cook over a period of 42 days (Table 1). During the research cruise nutrient samples were analysed daily, thus these CRM analyses were conducted in a typical research environment where the analysts were analysing hundreds of samples per day on-board a ship. The instrument was calibrated daily with six standards encompassing the expected concentration range of collected samples. The limit of detection was defined as 3 times the standard deviation of 20 replicates of the lowest concentration standard for each calibration during the research cruise. The limit of detection varied throughout the cruise, but ranged from 0.04 to $0.1 \mu \mathrm{M}, 0.02$ to $0.035 \mu \mathrm{M}$ and 0.04 to $0.11 \mu \mathrm{M}$ for $\Sigma \mathrm{NOx}, \mathrm{PO}_{4}{ }^{3-}$ and $\mathrm{Si}(\mathrm{OH})_{4}$ respectively. The concentration of samples analysed ranged from $<\mathrm{LoD}-38.93 \mu \mathrm{M},<\mathrm{LoD}-2.56 \mu \mathrm{M}$ and 0.29-131.25 $\mu \mathrm{M}$ for $\Sigma \mathrm{NOx}, \mathrm{PO}_{4}{ }^{3-}$ and $\mathrm{Si}(\mathrm{OH})_{4}$ respectively.

The combined uncertainties and the concentration range over which they were calculated are displayed in Table 2; the combined uncertainty for $\Sigma \mathrm{NOx}$ analyses was determined as $1.5 \%$, for $\mathrm{PO}_{4}{ }^{3-}$ analyses to be $3.7 \%$ and for $\mathrm{Si}(\mathrm{OH})_{4}$ analyses to be $2.4 \%$. Systematic bias accounted for $61 \%$ ( $\Sigma \mathrm{NOx}), 61 \%\left(\mathrm{PO}_{4}{ }^{3-}\right)$ and $47 \%\left(\mathrm{Si}(\mathrm{OH})_{4}\right)$ of the combined uncertainty. Thus approximately half of the analytical uncertainty is not accounted for if systematic bias is excluded from the estimate. On 24 occasions during the research cruise, two analysts collected 10 individual sample aliquots from the same Niskin water sampler that is used to collect seawater at depth in the ocean. These aliquots were then analysed in sequence, and therefore the variability in these results will be the outcome of uncertainties associated with the sampling procedure from the Niskin sampler and uncertainties associated with short-term analytical reproducibility [46]. For the concentration range over which the combined uncertainties were calculated ( $\Sigma$ NOx 5.63-36.66 $\mu \mathrm{M}, \mathrm{PO}_{4}{ }^{3-} 0.46-2.58 \mu \mathrm{M}$ and $14.27-111.85 \mu \mathrm{M}$ $\left.\mathrm{Si}(\mathrm{OH})_{4}\right)$, the relative standard deviation resulting from analyses of 10 samples was always less than the combined analytical uncertainty estimate (Fig. 2), confirming the necessity to account for systematic bias to calculate a realistic analytical uncertainty. However, at lower concentrations, close to the limit of detection, the analytical uncertainty increases and therefore may be larger than the combined uncertainty 


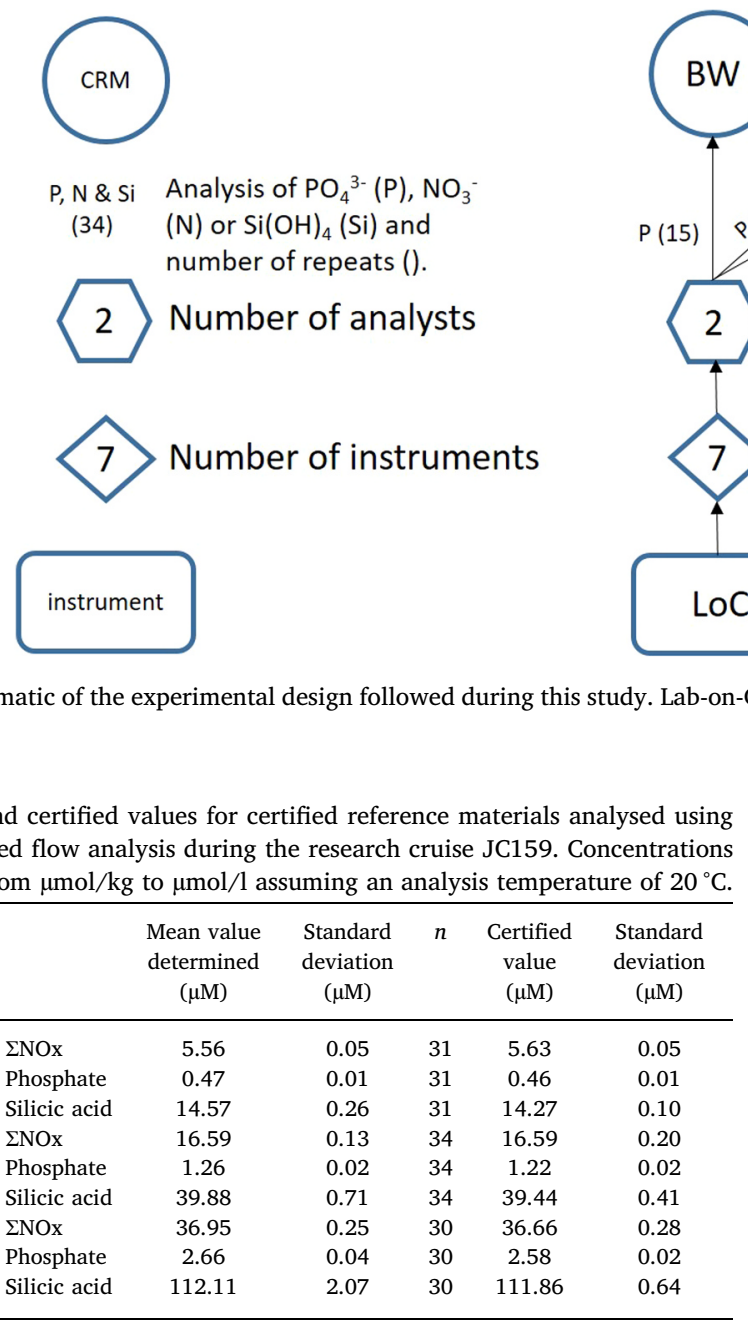

Table 2

The combined uncertainty estimate for each analytical technique. $u(R w)$ is the uncertainty resulting from within laboratory reproducibility. $\mathrm{u}$ (bias) is the uncertainty resulting from systematic bias. $\mathrm{u}_{\mathrm{c}}$ is the resulting combined uncertainty. Conc Range is the concentration range of CRMs analysed. * Estimate calculated using previously published CRM data [37]. Values in brackets are the uncertainty estimates if outliers (see text for details) are included in the calculation.

\begin{tabular}{cllll}
\hline & & LNOx & Phosphate & Silicic acid \\
\hline Gas Segmented Flow & $\mathrm{u}(\mathrm{Rw})(\%)$ & 0.83 & 2.03 & 1.79 \\
(Shipboard) & $\mathrm{u}(\mathrm{bias})(\%)$ & 1.30 & 3.13 & 1.58 \\
& $u_{c}(\%)$ & 1.5 & 3.7 & 2.4 \\
& Conc & $5.63-36.66$ & $0.46-2.58$ & $14.27-111.85$ \\
& Range & & & \\
Gas Segmented Flow & $(\mu \mathrm{M})$ & & & \\
& $\mathrm{u}(\mathrm{Rw})(\%)$ & $3.33(7.57)$ & $3.36(6.84)$ & n.d \\
& $\mathrm{u}(\mathrm{bias})(\%)$ & $1.68(2.95)$ & $1.69(2.37)$ & n.d \\
& $u_{c}(\%)$ & $3.7(8.1)$ & $3.8(7.2)$ & n.d \\
& Conc & $5.63-44.43$ & $0.46-3.13$ & n.d \\
& Range & & & \\
& $(\mu \mathrm{M})$ & & & n.d. \\
Lab-on-Chip Analyser & $\mathrm{u}(\mathrm{Rw})(\%)$ & $3.73(5.24)$ & $1.55^{*}$ & n.d. \\
& $\mathrm{u}(\mathrm{bias})(\%)$ & $3.19(2.36)$ & $5.95^{*}$ & n.d. \\
& $u_{c}(\%)$ & $4.9(5.8)$ & $6.1^{*}$ & \\
& Conc & $5.63-44.43$ & $0.46-1.541$ & n.d \\
& Range & & & \\
& $(\mu \mathrm{M})$ & & &
\end{tabular}
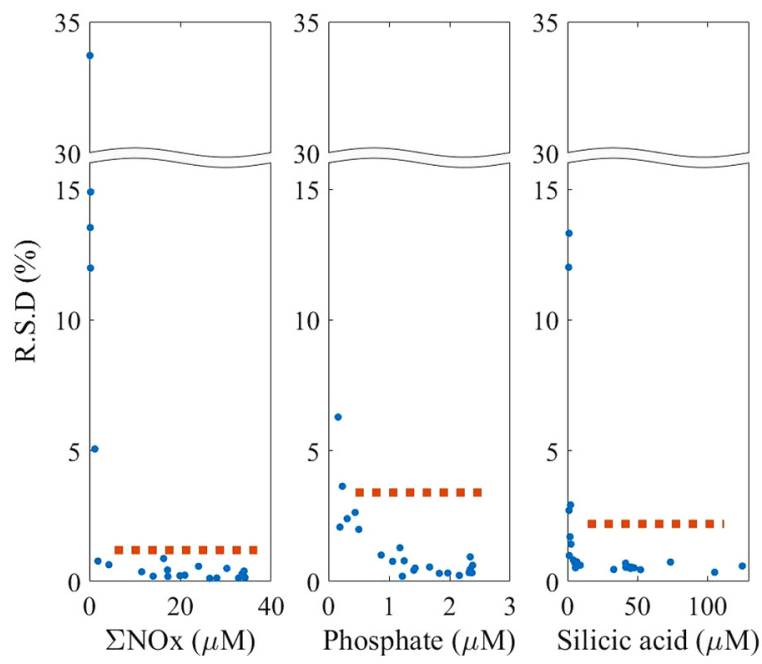

Fig. 2. The mean concentration and relative standard deviation (R.S.D.) calculated from the analysis of 10 samples collected from the same Niskin water sampler (blue symbols). This approach incorporates uncertainties associated with sampling and short term analytical reproducibility. One data point with a mean phosphate concentration of $0.01 \mu \mathrm{M}$ was removed as it was deemed to be below the limit of detection. The dashed orange line denotes the combined uncertainty estimate calculated in this study $(\mathrm{k}=1)$. This approach incorporates uncertainties associated within laboratory reproducibility and systematic bias. (For interpretation of the references to color in this figure legend, the reader is referred to the web version of this article).

calculated using CRMs with higher macronutrient concentrations [34]. It is therefore imperative that the range over which the combined uncertainty is calculated is reported alongside the value itself.

We consider that the combined uncertainties presented here for ship board gas segmented flow analysis (1.5-3.7\%) are remarkably small, particularly given the challenges associated with making high quality nutrient measurements whilst at sea (e.g. reliance on pre-weighed salts and reagents, moving laboratory, analyst fatigue). Precision alone for marine nutrient measurements has been reported as typically $\sim 2-3 \%$ $[18,47]$. In comparison, reported values for combined uncertainties associated with trace metal measurements, albeit at sub-nanomolar concentrations, range from $7.5 \%$ to $12 \%[20,23]$. To establish whether our calculated measurement uncertainties can be considered typical, a smaller set of CRM analyses was conducted in a separate laboratory. 
Table 3

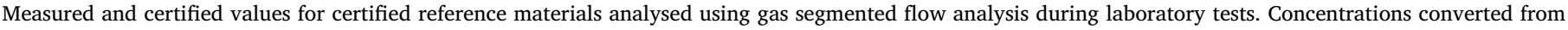

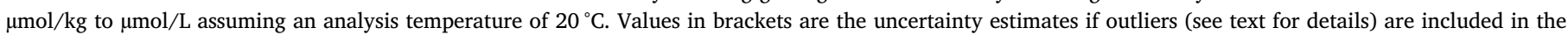
calculation.

\begin{tabular}{|c|c|c|c|c|c|c|}
\hline & & Mean value determined $(\mu \mathrm{M})$ & Standard deviation $(\mu \mathrm{M})$ & $n$ & Certified value $(\mu \mathrm{M})$ & Standard deviation $(\mu \mathrm{M})$ \\
\hline \multirow[t]{2}{*}{ Kanso CD } & $\Sigma \mathrm{NOx}$ & $5.57(5.80)$ & $0.26(0.61)$ & $5(6)$ & 5.63 & 0.05 \\
\hline & Phosphate & $0.45(0.47)$ & $0.02(0.04)$ & $5(6)$ & 0.46 & 0.01 \\
\hline \multirow[t]{2}{*}{ Kanso BZ } & $\Sigma \mathrm{NOx}$ & $45.20(45.56)$ & $0.23(0.91)$ & $5(6)$ & 44.41 & 0.34 \\
\hline & Phosphate & $3.13(3.14)$ & $0.05(0.06)$ & $5(6)$ & 3.13 & 0.03 \\
\hline
\end{tabular}

Table 4

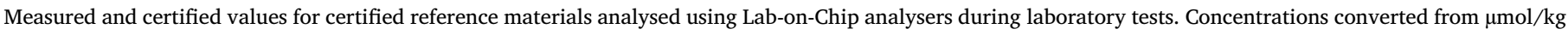
to $\mu \mathrm{mol} / \mathrm{L}$ assuming an analysis temperature of $20^{\circ} \mathrm{C}$. * Previously published CRM data [37].

\begin{tabular}{|c|c|c|c|c|c|c|}
\hline & & Mean value determined $(\mu \mathrm{M})$ & Standard deviation $(\mu \mathrm{M})$ & $n$ & Certified value $(\mu \mathrm{M})$ & Standard deviation $(\mu \mathrm{M})$ \\
\hline \multirow[t]{2}{*}{ Kanso CD } & $\Sigma \mathrm{NOx}$ & 5.48 & 0.22 & 10 & 5.63 & 0.05 \\
\hline & Phosphate* & 0.42 & 0.01 & 5 & 0.46 & 0.01 \\
\hline \multirow[t]{2}{*}{ Kanso BZ } & $\Sigma \mathrm{NOx}$ & 42.85 (43.59) & $1.49(2.73)$ & $9(10)$ & 44.43 & 0.34 \\
\hline & Phosphate & n.d. & n.d. & n.d. & 3.13 & 0.03 \\
\hline \multirow[t]{2}{*}{ Kanso BW } & $\Sigma \mathrm{NOx}$ & n.d & n.d & n.d & 25.19 & 0.20 \\
\hline & Phosphate $^{*}$ & 1.57 & 0.06 & 15 & 1.58 & 0.01 \\
\hline
\end{tabular}

These analyses yielded combined uncertainties of 3.7-3.8\% (Table 2), only marginally larger than our extensive ship board analyses, suggesting that such combined uncertainties values can be consistently achieved when the analysis is routinely conducted by trained analysts. The second set of analysis also highlighted an additional advantage of regularly analysing CRMs, which is the ability to identify outliers. Application of the International Organization for Standardization (ISO) approved Grubbs test for outliers identified an extreme analysed $\Sigma \mathrm{NOx}$ concentration for the both CD-KANSO and BZ-KANSO CRM on 26th June 2018; hence these values were excluded from the uncertainty calculation (Table 3; see Supporting information). On the same day the estimated $\mathrm{PO}_{4}{ }^{3-}$ concentrations for both CD-KANSO and BZ-KANSO CRM were also the largest determined within the dataset. Together, these results indicate that there existed an additional source of systematic uncertainty common to both measurements on 26th June 2018. Therefore, although the $\mathrm{PO}_{4}{ }^{3-}$ values did not fail the Grubbs test, they were still excluded from the calculation. Including the extreme values in the calculation resulted in much larger estimated combined uncertainties $\left(8.1 \%\right.$ for $\Sigma \mathrm{NOx} \& 7.2 \%$ for $\mathrm{PO}_{4}{ }^{3-}$, Table 2$)$. If this information is reviewed in real time it would allow the analyst to recalibrate before analysing samples. Alternatively, the analyst can retrospectively flag any sample data generated on such a day as suspected of being of suspect quality.

A realistic estimate of analytical uncertainty becomes increasingly important with a higher number of data manipulations. For instance, observing changes and patterns in nutrient stoichiometry is a common approach used to investigate marine biogeochemical processes [e.g. $3,5]$. Taking the combined analytical uncertainty values for measurements made using gas segmented flow analysis on-board ship results in $\mathrm{N}: \mathrm{P}, \mathrm{N}: \mathrm{Si}$ and P:Si ratios with uncertainties of $3.6 \%, 2.5 \%$ and $4 \%$, respectively. This information can be used to aid interpretation of the dataset, allowing the investigator to more accurately determine whether environmental processes drive observed changes in nutrient stoichiometry, or whether they may be artefacts resulting from analytical uncertainty.

The approach presented in this manuscript may be particularly useful for long term time series measurements. Changes to an analytical procedure over time, including changing analysts and analytical instrumentation, may contribute to measurement uncertainty. The primary function of a time series is to examine the temporal variability at a specific location. Therefore, applying an adjustment based on climatological average values risks removing the variability the scientist is aiming to observe. For instance, nutrient concentrations from the
DYFAMED time-series station in the North West Mediterranean were pooled by month to generate monthly climatologies. Extreme values were then removed from these datasets; $13 \%, 14 \%$ and $10 \%$ of $\Sigma \mathrm{NOx}$, $\mathrm{PO}_{4}{ }^{3-}$ and $\mathrm{Si}(\mathrm{OH})_{4}$ data, respectively, were removed. Whilst this monthly climatology approach likely preserves the effect of seasonal to decadal processes, it risks removing the effect of processes occurring on shorter time scales [48]. Examples of such processes include downwelling and upwelling events driven by mesoscale and sub-mesoscale processes [e.g. 49,50], phytoplankton blooms that can dramatically reduce inorganic nutrient concentrations on time scales of days [e.g. $25,39,51]$ and, to a lesser degree, atmospheric deposition that can release measureable quantities of inorganic nutrients to seawater [e.g. 52,53]. In addition, at coastal time series, such as the L4 station of the Western Channel Observatory (Plymouth, UK), variability in river discharge can influence nutrient concentrations over timescales of days [54]. The approach presented here would allow poor quality data to be identified without the risk of removing extreme data that result from such short term processes.

\subsection{Lab-on-Chip analysers}

The LoC analysers used in this study are designed and assembled at the National Oceanography Centre, Southampton. In this study, 7 individual LoC $\Sigma$ NOx sensors were used to analyse CRMs during laboratory testing by two analysts over a period of two months (Table 4). The analysis of the CRM KANSO-CD was conducted using all methods described in this paper, therefore the results can be treated as an analytical inter-comparison (Fig. 3). There was excellent agreement between all three instruments (Gas segmented flow bench top system and LoC) with no statistically significant difference between mean $\Sigma \mathrm{NOx}$ values ( 1 way ANOVA, $p=0.05$ ). The results presented here provide further evidence that LoC platforms produce data that is directly comparable with traditional gas segmented flow techniques $[36,38,39]$. In doing so they provide a powerful tool with which to augment traditional sampling approaches.

$\mathrm{A} \mathrm{PO}_{4}{ }^{3-}$ analyser is being developed but is at a lower technology readiness level (TRL 7; Table S1) than the $\Sigma$ NOx analyser (TRL 8) and therefore not at the developmental stage required for a study such as this; a more detailed combined uncertainty estimate for the $\mathrm{PO}_{4}{ }^{3-}$ analyser will be reported in a subsequent study. To give an indication of the combined uncertainty associated with measurements made using early versions of the $\mathrm{PO}_{4}{ }^{3-}$ analyser, CRM measurements made with two $\mathrm{LoC} \mathrm{PO}_{4}{ }^{3-}$ analysers during laboratory testing are taken from Grand 


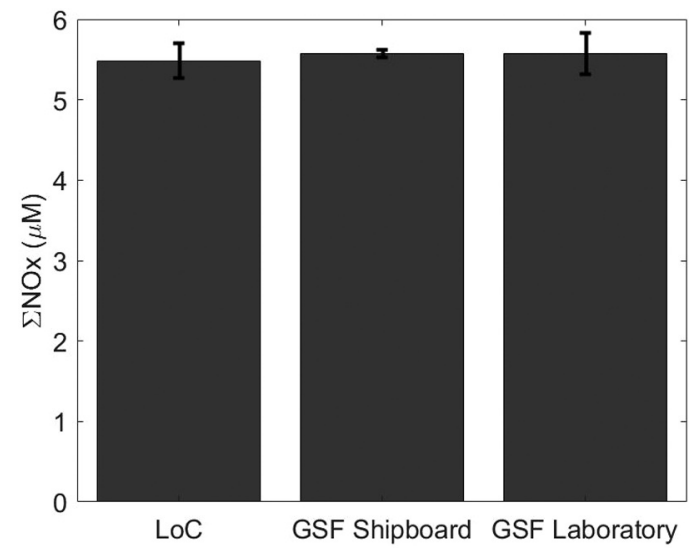

Fig. 3. The mean $\Sigma$ NOx concentration ( \pm 1 S.D.) for CRM KANSO-CD determined using gas segmented flow analysis (GSF) and Lab-on-Chip analysers (LoC). The certified value is $5.63 \pm 0.05 \mu \mathrm{M}$.

et al. [37] (Table 4). An additional LoC sensor is in development for Si $(\mathrm{OH})_{4}$ measurements; uncertainty data for this will be reported when the $\mathrm{Si}(\mathrm{OH})_{4}$ analyser technology is published.

For $\Sigma$ NOx LoC platforms, the combined uncertainty resulting from multiple platforms was calculated to be $<5 \%$ (Table 2). The Grubbs test was used to test for suspected extreme values. One value for $\Sigma \mathrm{NOx}$ was identified as a suspected outlier, and removed from the uncertainty calculation. It should be noted that variability between analysers as a source of uncertainty has been quantified for the LoC and not for the bench top gas segmented flow analysers used in this study. Future LoC sampling campaigns will include multiple sensors to increase spatial and temporal coverage. For instance, Vincent et al. [39] integrated a LoC $\Sigma$ NOx platform into an autonomous underwater vehicle (AUV) to observe changes in $\Sigma \mathrm{NOx}$ distributions in the Celtic Sea. The AlterEco programme (http://altereco.ac.uk/) aims to expand on this approach to determine seasonal baseline characteristics of the North Sea. A key aspect is the deployment of multiple LoC $\Sigma \mathrm{NOx}$ analysers in AUVs over a period of $>1$ year. The combined uncertainty values presented here provide confidence that high quality data will be generated during sampling campaigns such as that conducted as part of the AlterEco programme. It is noted that additional sources of uncertainty will be present during deployments in the marine environment (e.g. temperature \& pressure changes, biofouling). However, recent deployments indicate that the LoC platforms compare well with traditional benchtop techniques in glacial [42], riverine [36] and marine environments [37-39] and are not adversely affected by variations in environmental parameters. For instance, a comparison of data generated from a 21 day deployment of a LoC $\Sigma$ NOx analyser in an AUV, with coincident measurements made using traditional water sampling and gas-segmented flow analyses yielded an uncertainty estimate of $1.2-4.9 \%$ for the concentration range $1.42-5.74 \mu \mathrm{M}$ [39].

\section{Conclusions and future recommendations}

Analytical techniques used for the determination of marine nutrient concentrations are becoming increasingly automated, which will increase the quantity of data produced. Consequently, there is a need for simple statistical methods that produce realistic measurement uncertainties. It is clear from results presented here and elsewhere that accounting for systematic bias is necessary to produce realistic uncertainty values. Therefore, the NordTest ${ }^{\mathrm{TM}}$ approach is an ideal method for quantifying combined measurement uncertainty. A current objective of SCOR working group 147 is "To promote the wider global use of reference materials by arranging workshops to actively encourage their use, and to provide training in analytical protocols and best practices, including sample preservation protocols, particularly targeted towards developing countries." (https://scor-int.org/group/147/). Providing that CRMs are routinely analysed, the approach presented here requires no additional laboratory analyses or costly inter-comparison efforts, and so there are no additional costs incurred, which also makes this an attractive approach for scientists in developing countries. Therefore, it is advocated that application of the NordTest ${ }^{\mathrm{TM}}$ approach presented in this study becomes part of 'best practice' and that the combined uncertainty estimate (and the concentration range over which it was calculated) should be reported alongside measurement data.

The statistical approach described here offers advantages in determining analytical uncertainties for the measurements undertaken by the LoC analysers. Combined uncertainties can be assessed as sensors are manufactured, providing an objective method to assess betweenanalyser variability. It is recommended that, as individual LoC technology matures to TRL 8, a rigorous assessment of measurement uncertainty is conducted. The approach described here presents a simple method to achieve this. In this study we calculated that the combined measurement uncertainty associated with data produced from multiple $\Sigma$ NOx LoC analysers is $<5 \%$. This demonstrates the high quality and repeatability of the manufacturing process and highlights the potential of autonomous LoC analysers to become routine measurement tools for determining marine nutrient concentrations.

\section{CRediT authorship contribution statement}

A.J. Birchill: Conceptualization, Methodology, Formal analysis, Investigation, Writing - original draft, Writing - review \& editing, Visualization, Supervision, Project administration. G. Clinton-Bailey: Conceptualization, Methodology, Formal analysis, Investigation, Writing - original draft, Writing - review \& editing, Visualization, Supervision, Project administration. R. Hanz: Methodology, Investigation, Writing - review \& editing. E. Mawji: Methodology, Investigation, Writing - review \& editing. T. Cariou: Investigation, Writing - review \& editing. C. White: Investigation, Writing - review \& editing. S.J. Ussher: Writing - review \& editing, Supervision, Resources, Funding acquisition. P.J. Worsfold: Methodology, Writing review \& editing, Funding acquisition, Project administration. E.P. Achterberg: Writing - review \& editing, Funding acquisition. M. Mowlem: Resources, Funding acquisition, Writing - review \& editing.

\section{Acknowledgments}

The authors declare no competing interests. This project has received funding from the European Union's Horizon 2020 research and innovation programme under the AtlantOS programme, grant agreement No. 633211. The project has received funding from the Natural Environment Research Council under the Nutrient Sensors on Autonomous Vehicles and ORCHESTRA programs (NE/P020798/1, NE/N018095/1).

\section{Credit authorship contribution statement}

Antony J. Birchill: Conceptualisation, Methodology, Formal Analysis, Investigation, Writing - Original Draft, Writing - Review \& Editing, Visualization, Supervision, Project Administration. Geraldine Clinton-Bailey: Conceptualisation, Methodology, Formal Analysis, Investigation, Writing - Original Draft, Writing - Review \& Editing, Visualization, Supervision, Project Administration. Rudolf Hanz: Methodology, Investigation, Writing - Review \& Editing. Edward Mawji: Methodology, Investigation, Writing - Review \& Editing. Thierry Cariou: Investigation, Writing - Review \& Editing. Caroline White: Investigation, Writing - Review \& Editing. Simon J. Ussher: Writing - Review \& Editing, Supervision, Resources, Funding Acquisition. Paul J. Worsfold: Methodology, Writing - Review \& Editing, Funding Acquisition, Project Administration. Eric P. 
Achterberg: Writing - Review \& Editing, Funding Acquisition. Matthew Mowlem: Resources, Funding Acquisition, Writing - Review \& Editing.

\section{Appendix A. Supporting information}

Supplementary data associated with this article can be found in the online version at doi:10.1016/j.talanta.2019.03.032.

\section{References}

[1] D. Pauly, V. Christensen, Primary production required to sustain global fisheries, Nature 374 (1995) 255-257, https://doi.org/10.1038/374255a0.

[2] T. Volk, M.I. Hoffert, Ocean carbon pumps: Analysis of relative strengths and efficiencies in ocean-driven atmospheric $\mathrm{CO}_{2}$ changes, in: E. Sundquist, W. Broecker (Eds.), The Carbon Cycle and Atmospheric $\mathrm{CO}_{2}$ : Natural Variations Archean to Present, American Geophysical Union, 1985, pp. 99-110.

[3] A.C. Redfield, The biological control of chemical factors in the environment, Am Sci. 46 (1958) 230A (205-221), 〈https://www.jstor.org/stable/27827150〉.

[4] T. Tyrrell, The relative influences of nitrogen and phosphorus on oceanic primary production, Nature 400 (1999) 525, https://doi.org/10.1038/22941.

[5] C. Moore, M. Mills, K. Arrigo, I. Berman-Frank, L. Bopp, P. Boyd, E. Galbraith, R. Geider, C. Guieu, S. Jaccard, Processes and patterns of oceanic nutrient limitation, Nat. Geosci. 6 (2013) 701, https://doi.org/10.1038/ngeo1765.

[6] D.M. Anderson, Turning back the harmful red tide, Nature 388 (1997) 513, https:// doi.org/10.1038/41415

[7] R.J. Diaz, R. Rosenberg, Spreading dead zones and consequences for marine ecosystems, Science 321 (2008) 926-929, https://doi.org/10.1126/science.1156401.

[8] P. Griess, Bemerkungen zu der abhandlung der HH. weselsky und benedikt "ueber einige azoverbindunge", Ber. Dtsch. Chem. Ges. 12 (1879) 426-428, https://doi. org/10.1002/cber.187901201117.

[9] M.D. Patey, M.J. Rijkenberg, P.J. Statham, M.C. Stinchcombe, E.P. Achterberg M. Mowlem, Determination of nitrate and phosphate in seawater at nanomolar concentrations, TrAC Trends Anal. Chem. 27 (2008) 169-182, https://doi.org/10. 1016/j.trac.2007.12.006

[10] M.B. Shinn, Colorimetric method for determination of nitrate, Ind. Eng. Chem. Anal. Ed. 13 (1941) 33-35, https://doi.org/10.1021/i560089a010.

[11] J. Murphy, J.P. Riley, A modified single solution method for the determination of phosphate in natural waters, Anal. Chim. Acta 27 (1962) 31-36, https://doi.org/10. 1016/S0003-2670(00)88444-5.

[12] K. Grasshoff, K. Kremling, M. Ehrhardt, Methods of Seawater Analysis, John Wiley \& Sons, 2009.

[13] J.D. Strickland, T.R. Parsons, A Practical Handbook of Seawater Analysis, Fisheries Research Board of Canada, Ottawa, 1972.

[14] E.A. Nagul, I.D. McKelvie, P. Worsfold, S.D. Kolev, The molybdenum blue reaction for the determination of orthophosphate revisited: opening the black box, Anal. Chim. Acta 890 (2015) 60-82, https://doi.org/10.1016/j.aca.2015.07.030.

[15] P. Worsfold, I. McKelvie, P. Monbet, Determination of phosphorus in natural waters: a historical review, Anal. Chim. Acta 918 (2016) 8-20, https://doi.org/10. 1016/j.aca.2016.02.047.

[16] D. Hydes, M. Aoyama, A. Aminot, K. Bakker, S. Becker, S. Coverly, A. Daniel, A. Dickson, O. Grosso, R. Kerouel, Determination of dissolved nutrients (N, P, SI) in seawater with high precision and inter-comparability using gas-segmented continuous flow analysers, in: E.M. Hood, C.L. Sabine, B.M. Sloyan, (Eds.) The GO-SHIP Repeat Hydrography Manual: A Collection of Expert Reports and Guidelines. Version 1, 2010

[17] V.V. Gouretski, K. Jancke, Systematic errors as the cause for an apparent deep water property variability: global analysis of the WOCE and historical hydrographic data, Prog. Oceanogr. 48 (2000) 337-402, https://doi.org/10.1016/S0079-6611(00) 00049-5.

[18] T. Tanhua, P. Brown, R. Key, CARINA: nutrient data in the Atlantic Ocean, Earth Syst. Sci. Data (2009) 7-24, https://doi.org/10.5194/essd-1-7-2009.

[19] J. Olafsson, A. Olsen, Nordic Seas nutrients data in CARINA, Earth Syst. Sci. Data 2 (2010) 205-213, https://doi.org/10.5194/essd-2-205-2010.

[20] I. Rapp, C. Schlosser, D. Rusiecka, M. Gledhill, E.P. Achterberg, Automated preconcentration of $\mathrm{Fe}, \mathrm{Zn}, \mathrm{Cu}, \mathrm{Ni}, \mathrm{Cd}, \mathrm{Pb}, \mathrm{Co}$, and $\mathrm{Mn}$ in seawater with analysis using high-resolution sector field inductively-coupled plasma mass spectrometry, Anal. Chim. Acta 976 (2017) 1-13, https://doi.org/10.1016/j.aca.2017.05.008.

[21] S. Rigaud, V. Puigcorbé, P. Cámara-Mor, N. Casacuberta, M. Roca-Martí, J. Garcia-Orellana, C. Benitez-Nelson, P. Masqué, T. Church, A methods assessment and recommendations for improving calculations and reducing uncertainties in the determination of $210 \mathrm{Po}$ and $210 \mathrm{~Pb}$ activities in seawater, Limnol. Oceanogr. Methods 11 (2013) 561-571, https://doi.org/10.4319/lom.2013.11.561.

[22] P.J. Worsfold, R. Clough, M.C. Lohan, P. Monbet, P.S. Ellis, C.R. Quétel, G.H. Floor, I.D. McKelvie, Flow injection analysis as a tool for enhancing oceanographic nutrient measurements-a review, Anal. Chim. Acta 803 (2013) 15-40, https://doi. org/10.1016/j.aca.2013.06.015.

[23] P.J. Worsfold, E.P. Achterberg, A.J. Birchill, R. Clough, I. Leito, M.C. Lohan, A. Milne, S.J. Ussher, Estimating uncertainties in oceanographic trace element measurements, Front. Mar. Sci. 5 (2019), https://doi.org/10.3389/fmars.2018 00515.

[24] G.H. Floor, R. Clough, M.C. Lohan, S.J. Ussher, P.J. Worsfold, C.R. Quétel,
Combined uncertainty estimation for the determination of the dissolved iron amount content in seawater using flow injection with chemiluminescence detection, Limnol. Oceanogr.: Methods 13 (2015) 673-686, https://doi.org/10.1002/lom3. 10057.

[25] A.J. Birchill, A. Milne, E.M.S. Woodward, C. Harris, A. Annett, D. Rusiecka, E.P. Achterberg, M. Gledhill, S.J. Ussher, P.J. Worsfold, Seasonal iron depletion in temperate shelf seas, Geophys. Res. Lett. 44 (2017) 8987-8996, https://doi.org/10. 1002/2017GL073881.

[26] N.L. Bindoff, J. Willebrand, V. Artale, A. Cazenave, J.M. Gregory, S. Gulev, K. Hanawa, C. Le Quéré, S. Levitus, Y. Nojiri, Observations: oceanic climate change and sea level, in: S. Solomon et al., (Eds.) Climate Change 2007: The Physical Science Basis: Contribution of Working Group I to the Fourth Assessment Report of the Intergovernmental Panel on Climate Change, Cambridge, UK, 2007, p. 385-433.

[27] A. Aminot, D. Kirkwood, Report on the results of the fifth ICES intercomparison exercise for nutrients in sea water, International Council for the Exploration of the Sea, Cooperative Research Report 213, Copenhagen, Denmark, 1995.

[28] A. Aminot, R. Kérouel, Reference material for nutrients in seawater: stability of nitrate, nitrite, ammonia and phosphate in autoclaved samples, Mar. Chem. 49 (1995) 221-232, https://doi.org/10.1016/0304-4203(95)00004-B.

[29] M. Aoyama, S. Becker, M. Dai, H. Daimon, L.I. Gordon, H. Kasai, R. Kerouel, N. Kress, D. Masten, A. Murata, Recent comparability of oceanographic nutrients data: results of a 2003 intercomparison exercise using reference materials, Anal. Sci. 23 (2007) 1151-1154, https://doi.org/10.2116/analsci.23.1151.

[30] M. Aoyama, C. Anstey, J. Barwell-Clarke, F. Baurand, S. Becker, M. Blum, S.C. Coverly, E. Czobik, F. d'Amico, I. Dahllof, inter-laboratory comparison study of a reference material for nutrients in seawater, Tech. Rep. Meteorol. Res. Inst. 60 (2010) (2008) 134, https://doi.org/10.11483/mritechrepo.60.

[31] D. Kirkwood, A. Aminot, M. Perttila, Report on the results of the ICES fourth intercomparison exercise for nutrients in sea water, International Council for the Exploration of the Sea, Cooperative Research Report 174, Copenhagen, Denmark, 1991.

[32] M. Aoyama, H. Ota, M. Kimura, T. Kitao, H. Mitsuda, A. Murata, K. Sato, Current status of homogeneity and stability of the reference materials for nutrients in seawater, Anal. Sci. 28 (2012) 911-916, https://doi.org/10.2116/analsci.28.911.

[33] V. Clancy, S. Willie, Preparation and certification of a reference material for the determination of nutrients in seawater, Anal. Bioanal. Chem. 378 (2004) 1239-1242, https://doi.org/10.1007/s00216-003-2473-1.

[34] E.V. Dafner, Segmented continuous-flow analyses of nutrient in seawater: intralaboratory comparison of Technicon AutoAnalyzer II and Bran + Luebbe continuous flow AutoAnalyzer III, Limnol. Oceanogr.: Methods 13 (2015) 511-520, https://doi.org/10.1002/lom3.10035.

[35] A.D. Beaton, C.L. Cardwell, R.S. Thomas, V.J. Sieben, F.-E. Legiret, E.M. Waugh, P.J. Statham, M.C. Mowlem, H. Morgan, Lab-on-chip measurement of nitrate and nitrite for in situ analysis of natural waters, Environ. Sci. Technol. 46 (2012) 9548-9556, https://doi.org/10.1021/es300419u.

[36] G.S. Clinton-Bailey, M.M. Grand, A.D. Beaton, A.M. Nightingale, D.R. Owsianka, G.J. Slavik, D.P. Connelly, C.L. Cardwell, M.C. Mowlem, A lab-on-chip analyzer for in situ measurement of soluble reactive phosphate: improved phosphate blue assay and application to fluvial monitoring, Environ. Sci. Technol. 51 (2017) 9989-9995, https://doi.org/10.1021/acs.est.7b01581.

[37] M.M. Grand, G.S. Clinton-Bailey, A.D. Beaton, A.M. Schaap, T.H. Johengen, M.N. Tamburri, D.P. Connelly, M.C. Mowlem, E.P. Achterberg, A lab-on-chip phosphate analyzer for long-term in situ monitoring at fixed observatories: optimization and performance evaluation in estuarine and oligotrophic coastal waters, Front. Mar. Sci. 4 (2017) 255, https://doi.org/10.3389/fmars.2017.00255.

[38] M. Yücel, A.D. Beaton, M. Dengler, M.C. Mowlem, F. Sohl, S. Sommer, Nitrate and nitrite variability at the seafloor of an oxygen minimum zone revealed by a novel microfluidic in-situ chemical sensor, PLoS One 10 (2015) e0132785, https://doi. org/10.1371/journal.pone.0132785.

[39] A.G. Vincent, R.W. Pascal, A.D. Beaton, J. Walk, J.E. Hopkins, E.M.S. Woodward, M. Mowlem, M.C. Lohan, Nitrate drawdown during a shelf sea spring bloom revealed using a novel microfluidic in situ chemical sensor deployed within an autonomous underwater glider, Mar. Chem. (2018), https://doi.org/10.1016/j marchem.2018.07.005.

[40] A.M. Nightingale, A.D. Beaton, M.C. Mowlem, Trends in microfluidic systems for in situ chemical analysis of natural waters, Sens. Actuators B: Chem. 221 (2015) 1398-1405, https://doi.org/10.1016/j.snb.2015.07.091.

[41] E.A. Bagshaw, A. Beaton, J.L. Wadham, M. Mowlem, J.R. Hawkings, M. Tranter, Chemical sensors for in situ data collection in the cryosphere, TrAC Trends Anal. Chem. 82 (2016) 348-357, https://doi.org/10.1016/j.trac.2016.06.016.

[42] A.D. Beaton, J.L. Wadham, J. Hawkings, E.A. Bagshaw, G. Lamarche-Gagnon, M.C. Mowlem, M. Tranter, High-resolution in situ measurement of nitrate in runoff from the Greenland Ice Sheet, Environ. Sci. Technol. 51 (2017) 12518-12527, https://doi.org/10.1021/acs.est.7b03121.

[43] A.D. Beaton, V.J. Sieben, C.F. Floquet, E.M. Waugh, S.A.K. Bey, I.R. Ogilvie, M.C. Mowlem, H. Morgan, An automated microfluidic colourimetric sensor applied in situ to determine nitrite concentration, Sens. Actuators B: Chem. 156 (2011) 1009-1014, https://doi.org/10.1016/j.snb.2011.02.042.

[44] B. Magnusson, T. Näykk, H. Hovind, M. Krysell, Handbook for calculation of measurement uncertainty in environmental laboratories (NT TR 537 - Edition 3.1): Oslo, Norway, 2012, p. 46.

[45] A.J. Birchill, N.T. Hartner, K. Kunde, B. Siemering, C. Daniels, D. González-Santana, A. Milne, S.J. Ussher, P.J. Worsfold, K. Leopold, S.C. Painter, M.C. Lohan, The eastern extent of seasonal iron limitation in the high latitude North Atlantic Ocean, Sci. Rep. 9 (2019) 1435, https://doi.org/10.1038/s41598-018-37436-3.

[46] R. Clough, G.H. Floor, C.R. Quétel, A. Milne, M.C. Lohan, P.J. Worsfold, 
Measurement uncertainty associated with shipboard sample collection and filtration for the determination of the concentration of iron in seawater, Anal. Methods 8 (2016) 6711-6719, https://doi.org/10.1039/C6AY01551D.

[47] C.E. Davis, S. Blackbird, G. Wolff, M. Woodward, C. Mahaffey, Seasonal organic matter dynamics in a temperate shelf sea, Prog. Oceanogr. (2018), https://doi.org/ 10.1016/j.pocean.2018.02.021.

[48] O. Pasqueron de Fommervault, C. Migon, F. D'Ortenzio, M. Ribera d'Alcalà, L. Coppola, Temporal variability of nutrient concentrations in the northwestern Mediterranean sea (DYFAMED time-series station), Deep Sea Res. Part I: Oceanogr. Res. Pap. 100 (2015) 1-12, https://doi.org/10.1016/j.dsr.2015.02.006.

[49] W.J. Jenkins, D.J. McGillicuddy, D.E. Lott, The distributions of, and relationship between, 3He and nitrate in eddies, Deep Sea Res. Part II: Top. Stud. Oceanogr. 55 (2008) 1389-1397, https://doi.org/10.1016/j.dsr2.2008.02.006.

[50] G. Väli, V. Zhurbas, U. Lips, J. Laanemets, Submesoscale structures related to upwelling events in the Gulf of Finland, Baltic Sea (numerical experiments), J. Mar. Syst. 171 (2017) 31-42, https://doi.org/10.1016/j.jmarsys.2016.06.010.

[51] N. Mayot, F. D'Ortenzio, V. Taillandier, L. Prieur, O.P. de Fommervault, H. Claustre,
A. Bosse, P. Testor, P. Conan, Physical and biogeochemical controls of the phytoplankton blooms in north western Mediterranean Sea: a multiplatform approach over a complete annual cycle (2012-2013 DEWEX experiment), J. Geophys. Res.: Oceans 122 (2017) 9999-10019, https://doi.org/10.1002/2016JC012052.

[52] B. Herut, R. Collier, M.D. Krom, The role of dust in supplying nitrogen and phosphorus to the Southeast Mediterranean, Limnol. Oceanogr. 47 (2002) 870-878, https://doi.org/10.4319/lo.2002.47.3.0870.

[53] O. asqueron de Fommervault, C. Migon, A. Dufour, F. D'Ortenzio, F. Kessouri, P. Raimbault, N. Garcia, V. Lagadec, Atmospheric input of inorganic nitrogen and phosphorus to the Ligurian Sea: data from the Cap Ferrat coastal time-series station, Deep Sea Res. Part I: Oceanogr. Res. Pap. 106 (2015) 116-125, https://doi.org/10. 1016/j.dsr.2015.08.010

[54] A.P. Rees, S.B. Hope, C.E. Widdicombe, J.L. Dixon, E.M.S. Woodward, M.F. Fitzsimons, Alkaline phosphatase activity in the western English Channel: elevations induced by high summertime rainfall, Estuar. Coast. Shelf Sci. 81 (2009) 569-574, https://doi.org/10.1016/j.ecss.2008.12.005. 